OPEN ACCESS

Edited by:

Andrea Buettner,

Fraunhofer-Institut für

Verfahrenstechnik und Verpackung

(IN), Germany

Reviewed by:

Pangzhen Zhang,

The University of Melbourne, Australia Vesna Rastija

Faculty of Agriculture, University of

Osijek, Croatia

Michael Rychlik,

Technische Universität München,

Germany

*Correspondence:

Hua Li

lihuawine@nwsuaf.edu.cn

Hua Wang

wanghua@nwsuaf.edu.cn

Specialty section:

This article was submitted to

Food Chemistry

a section of the journal

Frontiers in Chemistry

Received: 20 June 2018

Accepted: 11 March 2019

Published: 02 April 2019

Citation:

Bi J, Li H and Wang H (2019) Delayed Bitterness of Citrus Wine Is Removed Through the Selection of Fining Agents and Fining Optimization.

Front. Chem. 7:185

doi: 10.3389/fchem.2019.00185

\section{Delayed Bitterness of Citrus Wine Is Removed Through the Selection of Fining Agents and Fining Optimization}

\author{
Jingying $B i^{1,2}$, Hua $\mathrm{Li}^{1 *}$ and Hua Wang ${ }^{1 *}$ \\ ${ }^{1}$ College of Enology, Northwest A \& F University, Yangling, China, ${ }^{2}$ Ningxia Polytechnic, Ningxia Vocational Education Park, \\ Yinchuan, China
}

"Delayed bitterness" (DB) in citrus wine is caused by limonoids and determines the acceptability to consumers. In this study, a variety of fining agents, specifically gelatin, agar, chitosan, bentonite, the crosslinking agent polyvinylpyrrolidone (PVPP), diatomite, and casein, were evaluated for their ability to lower DB in citrus wine. Factorial experiments with three factors at four levels $\left(\mathrm{L}_{3}^{4}\right)$ and with two factors at three levels $\left(\mathrm{L}_{2}^{3}\right)$ were used to determine the optimal effect. We found that a mixture of agar (125 mg/L) and gelatin $(30 \mathrm{mg} / \mathrm{L})$ not only decreased the limonoid concentration and clarified the liquor, but also increased the precipitation content, retention rate of ascorbic acid, and antioxidant capacity. After treatment, the quality of the citrus wine was improved, and a few volatile chemical compounds were lost. We determined that agar and gelatin were the best fining agents for reducing DB in citrus wine.

Keywords: citrus wine, delayed bitterness, limonoid, fining agent, agar, gelatin

\section{INTRODUCTION}

Citrus (Citrus reticulata Blanco) represent the highest-value fruit crop in the world and the third largest contributor to the trade of agricultural products (Wu et al., 2006). According to the Food and Agriculture Organization of the United Nations (FAO), 17,848.22 million tons of citrus fruit was produced in the world in 2015, accounting for $27 \%$ of the world's total fruit production (FAO, 2016). Citrus is popular for its nutritious quality, distinctive flavor, and various bioactive compounds with antioxidant, antiallergic, antimicrobial, antiviral, anticancer, and antineoplastic properties (Roy and Saraf, 2006; Vieira et al., 2009). However, the processing of citrus products involves formidable problems, such as "delayed bitterness" (DB), which affects acceptability. DB is caused by a group of oxygenated tetranortriterpenoid compounds, named limonoids, which are commonly found in species from the Rutaceae, Meliaceae, and Cneoraceae families, and less frequently, from the Simaroubaceae family (Champagne et al., 1992; Roy and Saraf, 2006). As a salt of limonoic acid, A-ring lactone is found in fruit tissues; however, when the fruit is crushed, juiced, and frozen, the combined action of the juice acids and the enzyme limonin-D-ring hydrolase (EC 3.1.1.36) converts the tasteless A-ring lactone to limonin, which is bitter (Maier et al., 1977, 1980; Puri, 1990; Berhow et al., 2000). Previous data revealed that the taste threshold level of limonin is $1 \mathrm{ppm}$ in distilled water and $6 \mathrm{ppm}$ in juices (Guadagni et al., 1973). Further, nomilin is thought to have only a minor contribution to the bitter taste of orange juice (Rouseff, 1982). Therefore, using appropriate technology in citrus processing is important to reduce bitterness in citrus juices below a threshold 
level for consumer acceptability. Although several chemical, physical, and microbiological methods have been devised and proposed to remove limonoids from citrus juice, very few of these methods have practical application. This is because debittering is achieved at a cost of nutritional quality, for example, through a reduction in the levels of ascorbic acid, naringin, hesperidin, or total phenolic compounds (Lee and Kim, 2003; Kranz et al., 2011) and negative effects on color, flavor, taste, texture, and stability.

Fining agents are routinely used at different stages of the winemaking process to counteract constituents that are considered to adversely affect juice or wine quality. The fining process relies on adding substances that induce flocculation and settling in turbid wine, or in wine with colloidal instability. A broad range of fining agents is available for use, and fining is a common practice in winemaking (Jackson, 2014).

The purpose of this study was to investigate different concentrations of several fining agents-namely gelatin, agar, chitosan, bentonite, PVPP, diatomite, and casein-as single factors, three factors at four levels $\left(\mathrm{L}_{3}^{4}\right)$, and two factors at three levels $\left(\mathrm{L}_{2}^{3}\right)$ in factorial-optimization experiments to evaluate their capacity to remove limonoids from citrus wine, which has not been previously reported. Our aim was to fundamentally test the hypothesis that specific fining agents are suitable to reduce the levels of DB compounds in citrus wine. To that end, three experiments were conducted: (a) a preliminary screening of seven fining agents at different concentrations to identify those that reduce DB levels in citrus wine; (b) testing of a subset of fining agents via $\mathrm{L}_{3}^{4}$ orthogonal trial on limonoid removal and turbidity reduction in citrus wine; and (c) final testing and optimization of the best-performing fining agents using a $\mathrm{L}_{2}^{3}$ experiment.

\section{EXPERIMENTAL}

\section{Fruit Materials}

Six-years old navel orange trees (Citrus sinensis L. Osbeck), representing the major cultivated variety among the different ecological types of citrus in China, approximately $2.5-3.0 \mathrm{~m}$ tall, from the Huacharm Co., Ltd. orchard located in Qu County, Sichuan, China $\left(\sim 30^{\circ} 85^{\prime} \mathrm{N}, 106^{\circ} 95^{\prime} \mathrm{E}\right)$ were chosen for this study. All fruits were harvested at commercial maturity, based on size, color, shape, weight, and the absence of physical injuries or infections. Navel oranges with a ${ }^{\circ}$ Brix maturity index of $11.90 \%$, total sugar (as glucose) of $58.46 \mathrm{~g} / \mathrm{L}$, titratable acidity (TA; as citric acid) of $7.20 \mathrm{~g} / \mathrm{L}$, a pH of 3.63 , and a juice rate of $41.72 \%$ were hand-picked in the middle of December 2016 and immediately transported to the College of Enology at Northwest A\&F University.

\section{Chemicals}

Standard limonin and 2,6-dichloroindophenol were purchased from Yuan Ye Bio-Tech Co., Ltd (Shanghai, China); 1,1-diphenyl-2-picrylhydrazyl (DPPH), 2,2'-azino-bis(3ethylbenzothiazoline-6-sulphonic acid) (ABTS), the 73 aroma standards and HPLC-grade methanol and acetonitrile were purchased from Sigma-Aldrich (Beijing, China). Ultra-pure water was obtained using a Milli-Q water purification system
(Millipore, Bedford, MA, USA). For the winemaking processes, agar, gelatin, chitosan, bentonite, PVPP, casein, and diatomite was purchased from McLean Bio-Tech Co., Ltd. (Shanghai, China), and yeast extract powder was obtained from Angel Yeast Co., Ltd. (Yichang, China).

\section{Winemaking Process}

Citrus wine samples were obtained in relatively small quantities (20 L) (Li, 2002). The peels of navel oranges were removed manually ensuring that the fruits were intact. The fruits were squeezed to separate the juice from the pulp and seeds. Then, citrus juice was sulfited by the addition of $100 \mathrm{mg} / \mathrm{L}$ potassium metabisulfite (corresponding to approximately $50 \mathrm{mg} / \mathrm{L}$ sulfur dioxide) in a glass bottle (20 L capacity). The juice obtained was treated with $20 \mathrm{mg} / \mathrm{L}$ of pectolytic enzyme preparation and stored for $48 \mathrm{~h}$ below $10^{\circ} \mathrm{C}$. The supernatant was adjusted to a temperature of $14-18^{\circ} \mathrm{C}$ before inoculation with $200 \mathrm{mg} / \mathrm{L}$ of active dry yeast powder. Sugar was added to increase the alcohol content to $12-13 \%(\mathrm{v} / \mathrm{v})$ during the vigorous fermentation period, and the fermentation temperature was maintained between 18 and $20^{\circ} \mathrm{C}$. The entire fermentation process lasted for 9-11 days. When residual sugar in the fermentation liquid dropped below $2 \mathrm{~g} / \mathrm{L}$, the wine was racked, sulfur dioxide (approximately $50 \mathrm{mg} / \mathrm{L}$ ) was added, and the bottle was sealed for $10-14$ days and subjected to aging. The citrus wine was subjected to different clarification treatments during its biological aging for one-and-a-half years.

The wine was analyzed for its ${ }^{\circ}$ Brix $(8.20 \%)$ and found to have a total sugar (as glucose) of $1.91 \mathrm{~g} / \mathrm{L}$, a TA (as citric acid) of 9.30 $\mathrm{g} / \mathrm{L}$, an alcohol content of $12.87 \%(\mathrm{v} / \mathrm{v})$, and a $\mathrm{pH}$ of 3.47 .

\section{Fining Agents and Clarification Experiments}

Unclarified citrus wine was treated with different concentrations of the following seven fining agents, namely gelatin $(15,30,45$, 60 , and $75 \mathrm{mg} / \mathrm{L})$, agar $(25,50,75,100,125$, and $150 \mathrm{mg} / \mathrm{L})$, chitosan $(200,400,600,800$, and $1,000 \mathrm{mg} / \mathrm{L})$, bentonite $(200$, $400,600,800$, and $1,000 \mathrm{mg} / \mathrm{L})$, PVPP $(20,40,60,80$, and 100 $\mathrm{mg} / \mathrm{L})$, diatomite $(250,500,750,1,000,1,250$, and $1,500 \mathrm{mg} / \mathrm{L})$, and casein $(150,300,450,600,750$, and $900 \mathrm{mg} / \mathrm{L})$, all of which were mixed well. Testing of each fining agent was performed at dosages commonly used in current winemaking practices ( $\mathrm{Li}$ et al., 2012). Aliquots (100 mL each) of wine samples were poured in colorimeter tubes and a single fining agent was added to each tube, followed by incubation in the dark at $4^{\circ} \mathrm{C}$ for $120 \mathrm{~h}$. All fining agent treatments were conducted in triplicate and included a control check wine (CK) that contained no fining agent. The supernatant was collected and analyzed for the limonoid concentration, turbidity, titratable acidity, $\mathrm{pH}, \mathrm{DPPH}, \mathrm{ABTS}$, and optical density at 450,520,570, and $630 \mathrm{~nm}$ (Pérez-Caballero et al., 2003). The remaining sample was centrifuged at $3,000 \times \mathrm{g}$ for $10 \mathrm{~min}$ and dried for the determination of constant weight and precipitation.

\section{Physicochemical Index Determination}

Turbidity, $\mathrm{pH}$, and total sugar, titratable acidity, $\mathrm{pH}$, alcohol, ascorbic acid, and precipitation contents were analyzed 
according to methods commonly used in the citrus industry (Kimball, 1991). Thermal stability was assessed after fining by filtering the citrus wine into a $250 \mathrm{~mL}$ volumetric flask containing iodine, using a wet and qualitative medium-speed filter. The sample was incubated in a thermostatic water bath for $72 \mathrm{~h}$ at $67-68^{\circ} \mathrm{C}$, and observations were made twice a day. If no precipitation was observed within $72 \mathrm{~h}$, the samples were considered to be heat stable (Wang et al., 2015). These measurements were all performed in triplicate.

\section{Extraction and Determination of Limonoid Equivalents}

Limonoids were selectively isolated from citrus juice via chloroform $\left(\mathrm{CHCl}_{3}\right)$ extraction (Andrew et al., 2007). The citrus wine samples were centrifuged at $1,500 \times \mathrm{g}$ for $10 \mathrm{~min}$ at $10^{\circ} \mathrm{C}$. A 1:2 mixture of clarified wine $(1 \mathrm{~mL})$ and $\mathrm{CHCl}_{3}(2 \mathrm{~mL})$ was transferred to a test tube, followed by ultrasonication $(30 \mathrm{~min}$ ), vortexing $(2 \mathrm{~min})$, and centrifugation at $1,500 \times \mathrm{g}$ for $10 \mathrm{~min}$ at $10^{\circ} \mathrm{C}$ to expedite the phase separation. Chloroform extracts were combined, and the solvent was removed at $40^{\circ} \mathrm{C}$ under slow and controlled nitrogen flow. Samples were reconstituted in $0.5 \mathrm{~mL}$ acetonitrile. Extractions were conducted in triplicate.

\section{Measurement of Limonoids by Spectrophotometry}

Limonoids were measured by spectrophotometry using the method of Abbasi et al. (2005). Limonin absorbance measurements were performed using a Cary 60 UV-visible spectrophotometer (Agilent Technologies, Inc., USA). Two milliliters of the acetonitrile phase was transferred to a test tube containing $5 \mathrm{~mL}$ of Ehrlich's reagent consisting of reagent $A$ and reagent $B(0.05 \mathrm{~mL}$ each $)$. Reagent A contained $125 \mathrm{mg}$ of 4-(dimethylamino)benzaldehyde, $65 \mathrm{~mL}$ of sulfuric acid, and $35 \mathrm{~mL}$ of absolute ethyl alcohol, which had been mixed and cooled, whereas reagent $\mathrm{B}$ consisted of $9.0 \mathrm{~g}$ of ferric trichloride dissolved in distilled water to a volume of $100 \mathrm{~mL}$. The mixture was kept at an ambient temperature for $20 \mathrm{~min}$ (Appendix in Supplementary Material) to gain maximum red color. Absorbance of the upper phase was assayed at $491 \mathrm{~nm}$ (Appendix in Supplementary Material).

\section{ABTS and DPPH Analysis}

The ABTS assay was based on the method of Re et al. (1999). ABTS was dissolved in water to reach a concentration of $7 \mathrm{mM}$. ABTS radical cations $\left(\mathrm{ABTS}^{\bullet 1}\right)$ were produced by mixing $5 \mathrm{~mL}$ of the ABTS stock solution with $88 \mu \mathrm{L}$ of potassium persulfate $(140 \mathrm{mM})$ in the dark at $15^{\circ} \mathrm{C}$ for $12-16 \mathrm{~h}$. The blue-green $\mathrm{ABTS}^{\bullet 1}$ solution was filtered through nylon syringe filters prior to use. To test the citrus wine, the $\mathrm{ABTS}^{\bullet 1}$ solution was diluted with ethanol to an absorbance at $734 \mathrm{~nm}$ of $0.70( \pm 0.02)$ and equilibrated to room temperature. An aliquot $(0.1 \mathrm{~mL})$ of the sample solution was added to $3.9 \mathrm{~mL} \mathrm{ABTS}^{\bullet 1}\left(\mathrm{~A}_{734 \mathrm{~nm}}=0.70 \pm\right.$ 0.02 ), followed by an $8 \mathrm{~min}$ reaction in the dark. Absorbance was measured using a Cary 60 UV-visible spectrophotometer (Agilent Technologies) at $734 \mathrm{~nm}$.

The spectrophotometric method employed for DPPH analysis is based on the free radical DPPH-scavenging activity determined using the method described by Gadow et al. (1997). Briefly, $1 \mathrm{~mL}$ of freshly prepared DPPH solution $(0.2 \mathrm{mM}$ DPPH in ethanol) and $1 \mathrm{~mL}$ of sample solution were mixed, followed by a $30 \mathrm{~min}$ reaction in the dark. Absorbance was measured with a Cary 60 UV-visible spectrophotometer (Agilent Technologies) at $517 \mathrm{~nm}$.

Appropriate solvent blanks were run in each assay. All determinations were carried out at least three times, and in triplicate, on each occasion and for each separate concentration for the standard and samples.

\section{Chromaticity and Color Analysis}

Citrus wine samples were centrifuged and filtered through $0.45-\mu \mathrm{m}$ filters prior to analysis. The color values of the wine were evaluated using CIELab color space (Pérez-Caballero et al., 2003) and were measured with a Cary 60 UV-visible spectrophotometer (Agilent Technologies) at four wavelengths (450, 520, 570, and $630 \mathrm{~nm}$ ). The values $L^{*}$ (lightness), $a^{*}$ (from red to green), and $b^{*}$ (from blue to yellow) (Pérez-Caballero et al., 2003), as well as $C^{*}$ (chroma), $H^{*}$ (hue-angle), and $E^{*}$ (color difference) (Ramos-Escudero et al., 2012), were calculated according to the following six formulae

$$
\begin{aligned}
L^{*} & =116 \times\left[\left(Y / Y_{10}\right)^{1 / 3}-0.1379\right] \\
a^{*} & =500 \times\left[\left(X / X_{10}\right)^{1 / 3}-\left(Y / Y_{10}\right)^{1 / 3}\right] \\
b^{*} & =200 \times\left[\left(Y / Y_{10}\right)^{1 / 3}-\left(Z / Z_{10}\right)^{1 / 3}\right] \\
C * & =\sqrt{(a *)^{2}+(b *)^{2}} \\
H^{*} & =\left[\operatorname{Arctan}\left(b^{*} / a^{*}\right)\right] \\
E^{*} & =\left[\left(L^{*}\right)^{2}+\left(a^{*}\right)^{2}+\left(b^{*}\right)^{2}\right]^{1 / 2}
\end{aligned}
$$

\section{Volatile Chemical Compound (VCC) Analysis}

Solid-phase micro-extraction gas chromatography-mass spectrometry (SPME-GC-MS) was used for VCC analysis. The experimental conditions employed were in accordance with those described by Wang et al. (2017), with minor differences.

\section{SPME Analysis}

All citrus wine samples were analyzed in $50 \mathrm{~mL}$ glass vials containing $20 \mathrm{~mL}$ of each sample, $2 \mathrm{~g}$ of $\mathrm{NaCl}$, and $60 \mu \mathrm{L}$ of the internal standard 2-octanol $(0.559$ $\mathrm{mg} / \mathrm{L}$ ). Then, magnetic agitation temperature control was needed for the vials. A magnetic stirring bar was placed in each vial, which provided agitation to the sample. Divinylbenzene/carboxen/polydimethylsiloxane $\quad(50 / 30 \mu \mathrm{m}$, StableFlex/SS [2 cm], Supelco, Bellefonte, PA., USA) was used as the solid-phase fiber for micro-extraction. SPME was performed at $40^{\circ} \mathrm{C}$ for $60 \mathrm{~min}$ before desorption of the analytes into the gas chromatograph injector.

\section{GC-MS Analysis}

A TRACE DSQ single quadrupole GC-MS (Thermo Finnigan, USA) system was used. For GC analysis, the analytical column consisted of a DB-Wax capillary column ( $30 \mathrm{~m}$ length, $0.25 \mathrm{~mm}$ inner diameter, $0.25 \mu \mathrm{m}$ film thickness; Agilent J\&W, Santa 
Clara, CA). He (flow rate of $1 \mathrm{~mL} / \mathrm{min}$ ) was used as a carrier gas. The temperature program was as follow: $40^{\circ} \mathrm{C}$ for $3 \mathrm{~min}$, increased to $160^{\circ} \mathrm{C}$ at a rate of $4^{\circ} \mathrm{C} / \mathrm{min}$, raised to $230^{\circ} \mathrm{C}$ at a rate of $7^{\circ} \mathrm{C} / \mathrm{min}$, and held at $230^{\circ} \mathrm{C}$ for $8 \mathrm{~min}$. The transfer line temperature was $230^{\circ} \mathrm{C}$ and the inlet temperature was $250^{\circ} \mathrm{C}$. Mass spectra were recorded in electron impact (EI) ionization mode. The ion source temperature was $230^{\circ} \mathrm{C}$. The mass range used for MS was 33-450 atomic mass units, and scanning was performed at $1 \mathrm{~s}$ intervals.

Identification was achieved by comparing the mass spectra obtained from the samples with those from pure standards injected under the same conditions, and by comparing the Kovats index and the mass spectra present in the Wiley MS Library Database, or in literature. The internal standard used for quantitation was 2-octanol $(0.559 \mathrm{mg} / \mathrm{L})$. Quantitative data were obtained for the identified compounds by interpolation of the relative areas vs. the internal standard area, in calibration graphs built for pure reference compounds. The concentrations of volatile compounds, for which there were no pure references, were obtained using the same calibration graphs as used for the compound with the most similar chemical structure, according to the formula and chemical character (Perestrelo et al., 2006; Li et al., 2008; Xi et al., 2011; Wang et al., 2017).

\section{Sensory Analysis}

Sensory analysis of citrus wine was performed in duplicate according to Peng et al. (2013). Bitterness and aroma characteristics were analyzed by 15 trained panelists, aged between 21 and 38 years old (nine females and six males). The panelists were undergraduate, master's, and doctoral students of the College of Enology at Northwest A\&F University, who provided informed consent to participate in the sensory tests for the present investigation, had no history of known taste disorders, and were trained in sensory experiments at regular intervals. In this study, the panelists were trained to detect citrus bitterness (mainly limonoid, nomilin, and naringin) using a 54-aroma kit (Le Nez du Vin ${ }^{\circledR}$, France) until their accuracy of identification for each trait exceeded $95 \%$. They were asked to describe citrus wine aroma using 4-6 terms from the aroma kit, which had been classified into different groups. In addition, the three-alternative forced-choice (3-AFC) test was used for threshold determination (Rousseff and Matthews, 1984); the panelists evaluated the citrus wine bitterness, aroma, overall impression, and other notable features of citrus wine, and graded the intensity of each characteristic using a five-point scale (1, very weak; 2 , weak; 3 , medium; 4 , intense; 5 , very intense; Glabasnia et al., 2018).

Participants signed an informed consent form and received a non-monetary gift for their participation. The participants, all non-smokers, were asked to refrain from eating, drinking, or chewing gum for $1 \mathrm{~h}$ prior to testing. To determine changes in the sensory properties of citrus wine samples that occurred during the fining process of eliminating limonoids, a sorting test was performed according to the sensory evaluation form of Cemeroglu (1992).
The data processed were a mixture of intensity and frequency of detection, which was calculated with the formula:

$$
M F \%=\sqrt{F(\%) I(\%)}
$$

where $F(\%)$ is the detection frequency of an aromatic attribute expressed as a percentage, and $I(\%)$ is the average intensity expressed as a percentage of the maximum intensity.

\section{Verification Test}

To demonstrate that using $125 \mathrm{mg} / \mathrm{L}$ agar and $30 \mathrm{mg} / \mathrm{L}$ gelatin as fining agents can reduce the concentration of limonoids in citrus wine, we adopted the citrus wine model system in this study (9.0 $\mathrm{g} / \mathrm{L}$ citric acid, $120 \mathrm{~mL} / \mathrm{L}$ anhydrous ethanol, and $20 \mathrm{~g} / \mathrm{L}$ glucose were diluted to $1 \mathrm{~L}$ in pure water). The $\mathrm{pH}$ was adjusted to 3.5 using $6 \mathrm{M}$ food-grade sodium hydroxide. These model systems were designed based on the compositions of sugars and acids, and the $\mathrm{pH}$ in navel orange wine (from average values obtained in 2013-2017). Then, limonin $(5,10,15,20$, and $25 \mathrm{mg} / \mathrm{L})$ and nomilin $(2,4,6,8$, and $10 \mathrm{mg} / \mathrm{L})$ were added, and the optimal combination of the fining agent was verified.

\section{Data Analysis}

All experiments were performed in triplicate. Means and standard deviations (SDs) were calculated using Excel 2007 (Microsoft, Redmond, WA, USA). Data were analyzed using Sigma Stat (SPSS Inc., Chicago, IL, USA) with significance at $P<0.05$. Results were subjected to analysis of variance (ANOVA) and Student's $t$-test.

\section{RESULTS AND DISCUSSION \\ Limonoids and Turbidity Analysis}

Based on our measurements of complexes formed with limonin and Ehrlich's reagent, we determined that the wavelength of maximum absorption, time for best color, and standard curve equation were $491 \mathrm{~nm}, 20 \mathrm{~min}$, and $\mathrm{Y}=8.18779 \mathrm{X}\left(R^{2}=0.99663\right)$, respectively. We also determined $\mathrm{Y}=0.00110 \mathrm{X}\left(R^{2}=0.99991\right)$ as the standard curve equation of turbidity and defined low turbidity as $<10$ nephelometric turbidity units (NTUs), moderate turbidity as 10-100 NTUs, and high turbidity as over 100 NTUs.

\section{Single-Factor Experiment Analysis}

Our findings from single-factor experiments clearly indicate that the limonoid content in most of the 38 samples tested was reduced after fining. Almost all of the fining agents tested removed limonoids to a certain extent from citrus wine (Figure 1). In particular, we found that a range of concentrations of gelatin, chitosan, and agar $(75,100,125$, and $150 \mathrm{mg} / \mathrm{L})$, as well as bentonite (400 and $600 \mathrm{mg} / \mathrm{L})$, and diatomite $(1,500$ $\mathrm{mg} / \mathrm{L}$ ) removed higher amounts of limonoids from citrus wine. In contrast, we found that the limonoid contents in samples after fining with casein $(750 \mathrm{mg} / \mathrm{L})$ and diatomite $(1,000 \mathrm{mg} / \mathrm{L})$ were comparable to that found in the CK1 (Control check wine sample for the single-factor test) sample. Similarly, we found that the turbidity of citrus wine samples decreased in most of the 38 samples tested after fining (Figure 1). All fining agents decreased the turbidity of citrus wine; particularly, certain concentrations of 

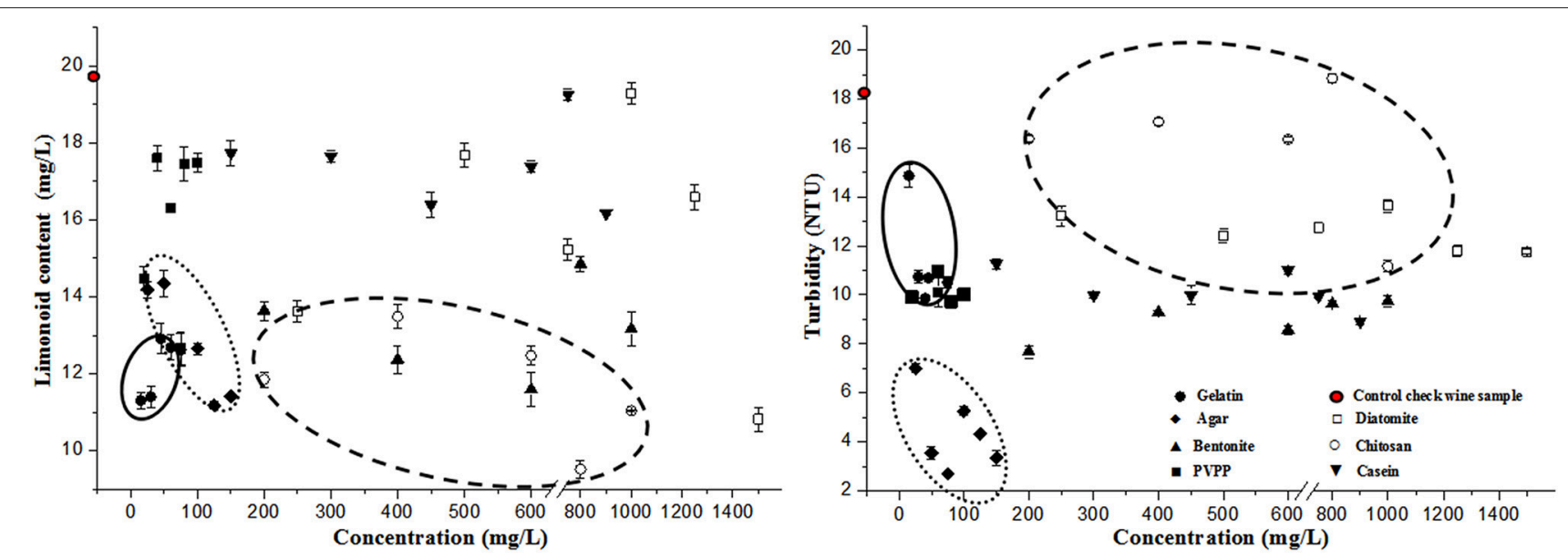

Gelatin

Agar

Chitosan _ - - - - - -

FIGURE 1 | Limonoid content and turbidity of citrus wine after fining with the indicated fining agents.

agar, bentonite, and PVPP (20, 40, and $80 \mathrm{mg} / \mathrm{L})$, and casein (300, 450, 750, and $900 \mathrm{mg} / \mathrm{L}$ ) markedly decreased wine turbidity. In contrast, we found the highest turbidity with chitosan $(800 \mathrm{mg} / \mathrm{L})$ and CK1, with NTU values of 18.83 and 18.29 , respectively.

As shown in Figure 1, agar, gelatin, and chitosan lowered the limonoid content and turbidity of citrus wine. A combination of fining agents can more effectively control nutrition loss and improve the flavor and stability of citrus wine. In fact, the clarification effect of a combination of fining agents is better than that found using single fining agents (Wang et al., 2016). Therefore, we next designed an orthogonal $\mathrm{L}_{3}^{4}$ experiment to determine the optimal combination of fining agent mixtures, which might complement each other and synergistically reduce the limonoid content and turbidity further.

\section{$\mathrm{L}_{3}^{4}$ Orthogonal Experiment Analysis}

Our findings from the $\mathrm{L}_{3}^{4}$ orthogonal experiment showed that the limonoid content in most citrus wine samples tested were reduced after fining (Table 1). Of note, we found significantly reduced limonoids with sample combination \#2 (10.74 mg/L) compared to that found in CK2 (Control check wine sample for the $\mathrm{L}_{3}^{4}$ test) $(16.59 \mathrm{mg} / \mathrm{L})$. The least effective fining agent combination was sample combination \#9, with a limonoid content of $12.49 \mathrm{mg} / \mathrm{L}$. We also found that all tested combinations of fining agents lowered turbidity, with the greatest reduction found in sample \#6 (4.89 NTUs), and the least reduction was found in sample \#2 (6.59 NTUs), as compared to a turbidity of 11.53 NTUs in CK2 (Table 1). Using ANOVA, we found that the three fining agents (gelatin, agar, and chitosan) affected the limonoid content in that order. However, chitosan, a natural cationic flocculent, had significant disadvantages for further use. In addition to higher cost, adding chitosan in excess is not conducive to clarification of the wine, as it confers a specific scent to the liquor body and lightens the color of the liquor due to pigment adsorption (Luo et al., 2007). Thus, agar and gelatin were chosen as fining agents for optimization in an $\mathrm{L}_{2}^{3}$ experiment.

\section{$\mathrm{L}_{2}^{3}$ Optimization Experiment Analysis}

From our $\mathrm{L}_{2}^{3}$ optimization experiment, we found that limonoids of most citrus wine samples were reduced after fining (Table 1). Of these, sample combinations \#15 (11.80 mg/L) and \#17 (13.13 $\mathrm{mg} / \mathrm{L}$ ) exhibited the greatest and least reduction respectively, although all tested samples had significantly lower limonoid contents, compared to that found in CK3 (16.34 mg/L). Similarly, we found that all tested wine samples had lower turbidity after fining, with the greatest reduction found in samples \#10 (3.75 NTUs) and \#15 (3.89 NTUs), and the least reduction found in sample \#14 (4.89 NTUs). All measures of turbidity in tested samples treated with fining agents were significantly lower than that found in CK3 (10.98 NTUs). Based on these findings, we determined that sample combination \#15, consisting of $125 \mathrm{mg} / \mathrm{L}$ agar and $30 \mathrm{mg} / \mathrm{L}$ gelatin, was the best combination.

\section{Thermal Stability and Optimization of Fining Agents}

We assessed the thermal stability after single-factor, $\mathrm{L}_{3}^{4}$, and $\mathrm{L}_{2}^{3}$ optimization experiments. We found that the citrus wine was light amber in color having no visible precipitation, no peculiar smell, and moderate turbidity (10-100 NTUs). We also evaluated the thermal stability based on results from our fining agentoptimization process and the identification of agar $(125 \mathrm{mg} / \mathrm{L})$ and gelatin $(30 \mathrm{mg} / \mathrm{L})$ as the optimal fining agents of citrus wine. Heat stability assessment of sample \#15 was performed in comparison to CK4 (the control check wine sample) (Table 2 and Figure 2).

\section{VCC Identification}

As shown in Table 3, several different VCCs were identified by SPME-GC-MS, including alcohols, esters, acids, aldehydes, and ketones. We detected 50 compounds in CK4 and 36 compounds in sample \#15, with total concentrations of $2.72 \times 10^{3}$ and $1.92 \times 10^{3} \mathrm{mg} / \mathrm{L}$, respectively. Based on our analysis, the VCCs 
TABLE 1 | Content of limonoids and turbidity of citrus wine after conducting $L_{3}^{4}$ and $L_{2}^{3}$ fining experiments.

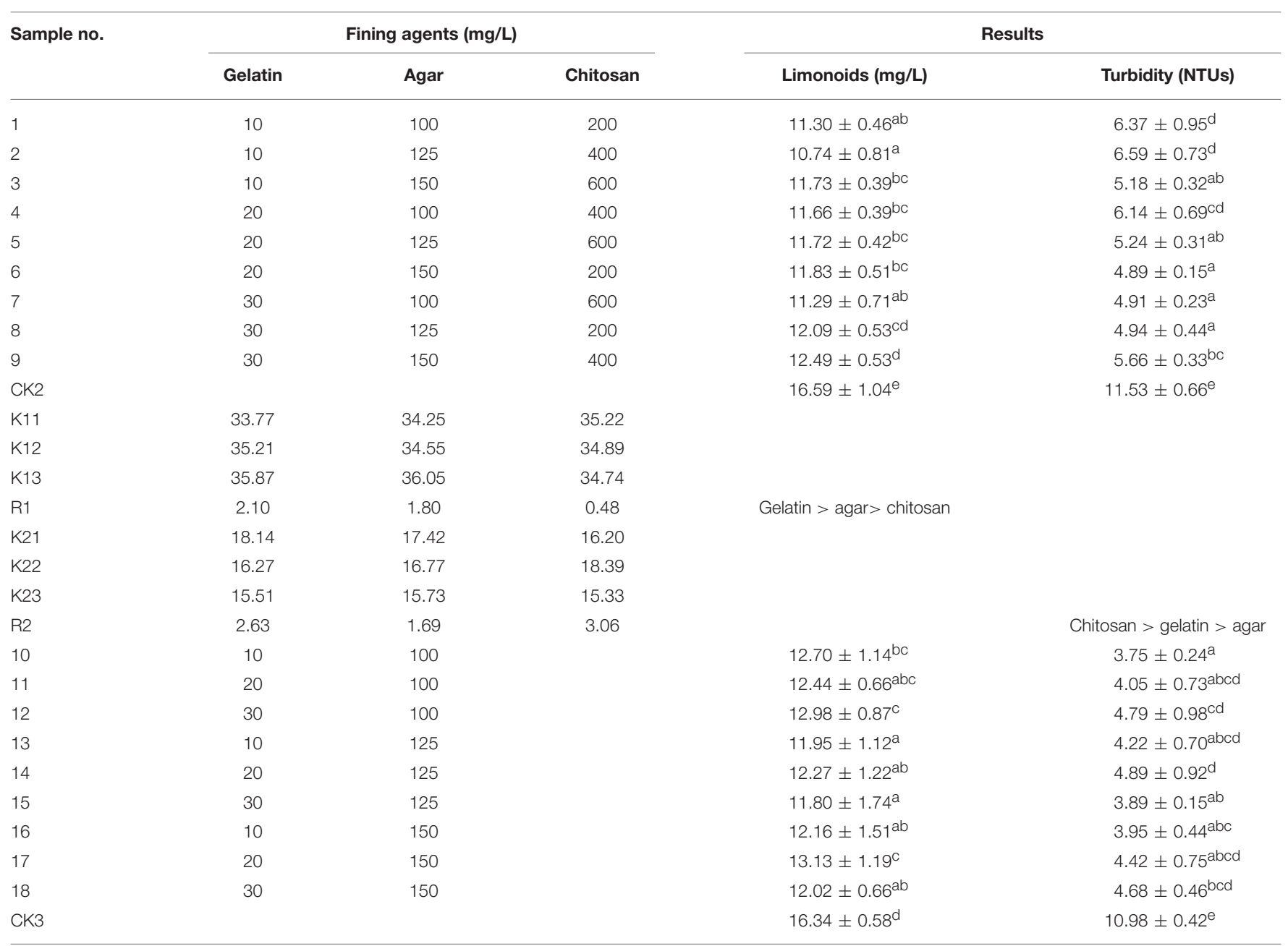

1-18: Treatment with combinations of different fining agents at different concentrations. Data in the same column not sharing the same letters reflect significant differences ( $P<0.05)$. CK3: control check wine sample for the $L_{2}^{3}$ test. $K$ ij: the average of all experimental results, $j$ factors, and $i$ levels. R1: The extreme level of limonoids in citrus wine samples treated

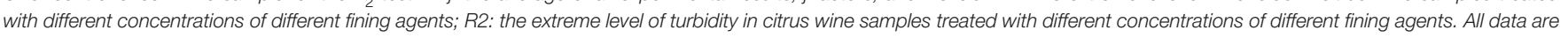
expressed as the mean $\pm S D$ of three replicates of 20 citrus wine samples.

of CK4 were clearly richer than those of sample \#15 and that this difference was due to the adsorption of VCCs by the fining agent.

With regard to their concentration and odor thresholds, the odor-active components with odor active values $(\mathrm{OAV}) \geq 1$ included 1-pentanol, methionol, phenylethanol, ethyl acetate, ethyl butanoate, isopentyl acetate, ethyl hexanoate, methyl octanoate, ethyl octanoate, ethyl decanoate, ethyl phenylacetate, diethyl succinate, ethyl phenylacetate, phenethyl acetate, hexanoic acid, octanoic acid, Nonanoic acid, n-decanoic acid, 9-decenoic acid, dodecanoic acid, 2-octanone, linalool, (-)-4terpineol, citronellol, geranylacetone, $\beta$-ionone, trans-nerolidol, farnesol, 2-methoxy-4-vinylphenol, and 2,4-di-tert-butylphenol. Table 4 shows different compounds with an OAV $\geq 1$ : with respect to the levels of alcohols, esters, acids, aldehydes, and ketones, terpenes, and others, either the individual concentration or the total concentration for CK4 was greater than that for sample \#15.

\section{Sensory Tasting Analysis}

Radial plots for each wine set are shown in Figure 2. These plots were used to identify potentially interesting sensory attributes. For set (a), the radial plot shows higher mean ratings for the attributes of color, condition (nose), purity (nose), intensity (nose), purity (palate), intensity (palate), length, and bitterness compared to those found for CK4. In contrast, we found a lower mean rating for the attributes of clarity, condition (palate), and balance for CK4. Therefore, the overall quality of CK4 citrus wine improved after treatment with the fining agent combination of sample \#15. Furthermore, CK4 wine had a higher mean rating in terms of aroma characteristics like citrus, apple, banana, peach, floral, traditional Chinese medicine, licorice, spices, and bitter almond compared to that found in fining agent combination sample \#15. Therefore, after fining, bitterness decreased, while characteristics of aroma and color (Granato et al., 2014) were lost to differing degrees. 
TABLE 2 | Physicochemical composition and CIELab parameters of citrus wine after fining and the heat stability experiment (HSE).

\begin{tabular}{|c|c|c|c|c|}
\hline & CK4 & Sample \#15 & CK4 after HSE & Sample \#15 after HSE \\
\hline Limonoids (mg/L) & $16.53 \pm 0.84$ & $10.54 \pm 0.61$ & - & - \\
\hline $\mathrm{pH}$ & $3.43 \pm 0.01$ & $3.56 \pm 0.01$ & - & - \\
\hline Precipitation content (g) & 0 & $0.15 \pm 0.00$ & - & - \\
\hline Turbidity (NTUs) & $11.23 \pm 0.46$ & $4.59 \pm 0.17$ & $91.68 \pm 1.90$ & $83.43 \pm 4.14$ \\
\hline ABTS ( $\mu \mathrm{mol} / \mathrm{L})$ & $3.63 \pm 0.04$ & $3.49 \pm 0.08$ & $1.95 \pm 0.08$ & $1.66 \pm 0.18$ \\
\hline$L^{*}$ & $95.61 \pm 0.23$ & $96.13 \pm 0.21$ & $78.55 \pm 0.89$ & $76.85 \pm 0.45$ \\
\hline$a^{*}$ & $-1.67 \pm 0.06$ & $-1.63 \pm 0.05$ & $6.72 \pm 0.48$ & $7.46 \pm 0.25$ \\
\hline$b^{*}$ & $19.74 \pm 0.55$ & $18.06 \pm 0.63$ & $50.43 \pm 0.72$ & $50.31 \pm 0.35$ \\
\hline$C^{*}$ & $19.81 \pm 0.54$ & $18.13 \pm 0.62$ & $50.88 \pm 0.78$ & $50.86 \pm 0.36$ \\
\hline
\end{tabular}

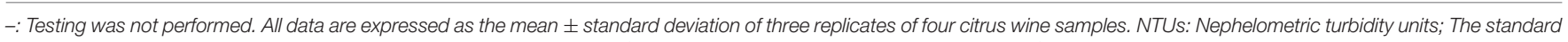

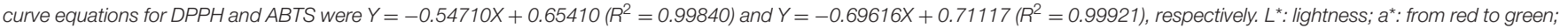
$b^{\star}$ : from blue to yellow; $C^{*}$ : chroma; $H^{*}$ : hue angle; and $E^{*}$ : color difference.
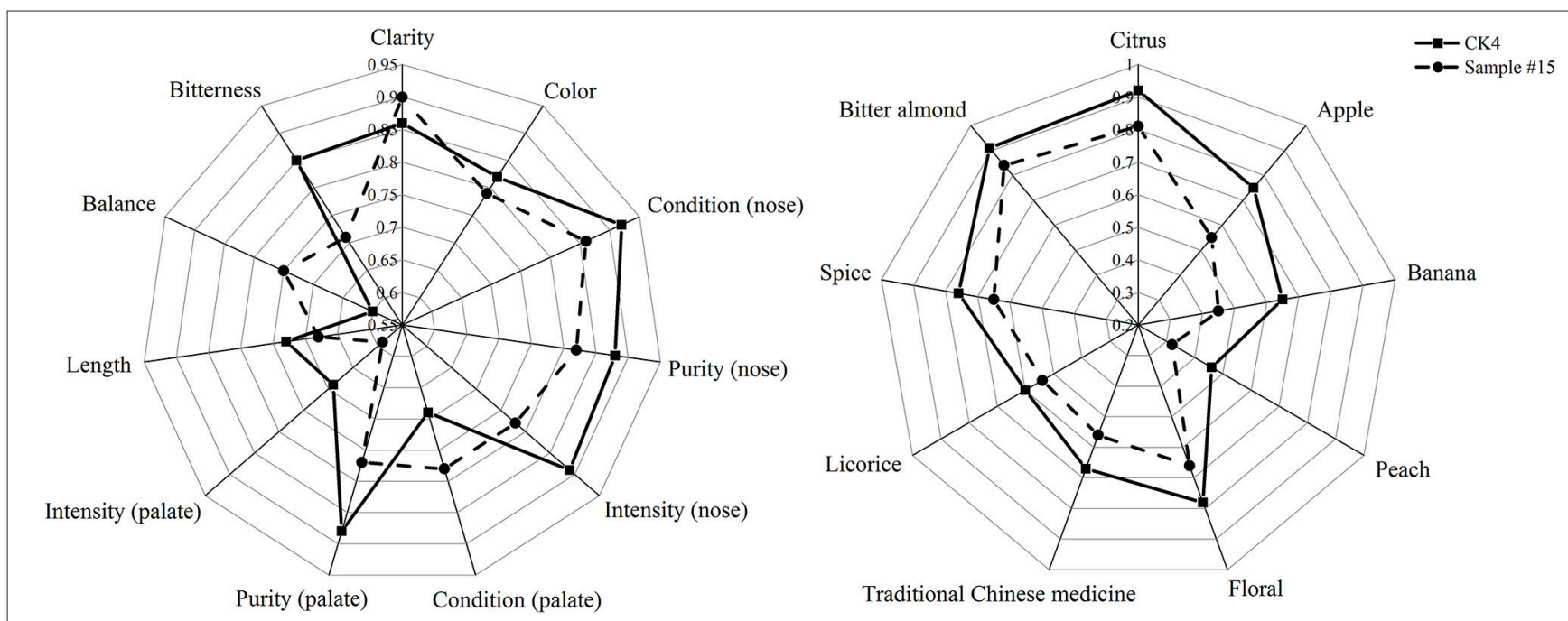

FIGURE 2 | Quantitative Descriptive Analysis (QDA) of (A) sensory quality and (B) aroma of sample \#15 and CK4.

Evaluation of our findings shows that several key characteristics of unfined wine and wine fined with different fining agents were different. A key finding related to DB is that the limonoid content was reduced by $36.24 \%$ in sample $\# 15$ compared to that in CK4. In addition, based on $\mathrm{pH}$ and total acidity measurements, the addition of fining agents definitively lowered the effect of acidity, and a combination of fining agents conferred a significant advantage in lowering the turbidity of citrus wine, as exemplified by the $59.13 \%$ reduction in turbidity found in sample \#15, when compared to that found in CK4. Based on our thermal stability experiment, we found moderate turbidity in all samples. We also found that the retention rate of ascorbic acid was $65.59 \%$ lower in sample \#15 than in CK4, indicating that the combination of gelatin and agar had a major effect on the adsorption and loss of ascorbic acid. From the thermal stability experiments, we also found that the retention rate of ascorbic acid decreased significantly, yet the rate was still higher for CK4 compared to that found in sample \#15. During our extensive analysis, we found that the amount of pure precipitate in sample \#15 was $0.15 \mathrm{~g}$ and that levels of ABTS and DPPH were slightly lower compared to those found in CK4, indicating that this combination of fining agents reduced the antioxidant capacity of the sample. The thermal stability experiments also showed that the antioxidative ability was greatly reduced in sample \#15 compared to that in CK4. As shown in our comparison in Table 2, we found increased $L^{*}$ and color brightness in sample \#15 compared to CK4, and following the thermal stability tests, brightness generally decreased, although 
TABLE 3 | Concentration of VCCs in CK4 and sample \#15.

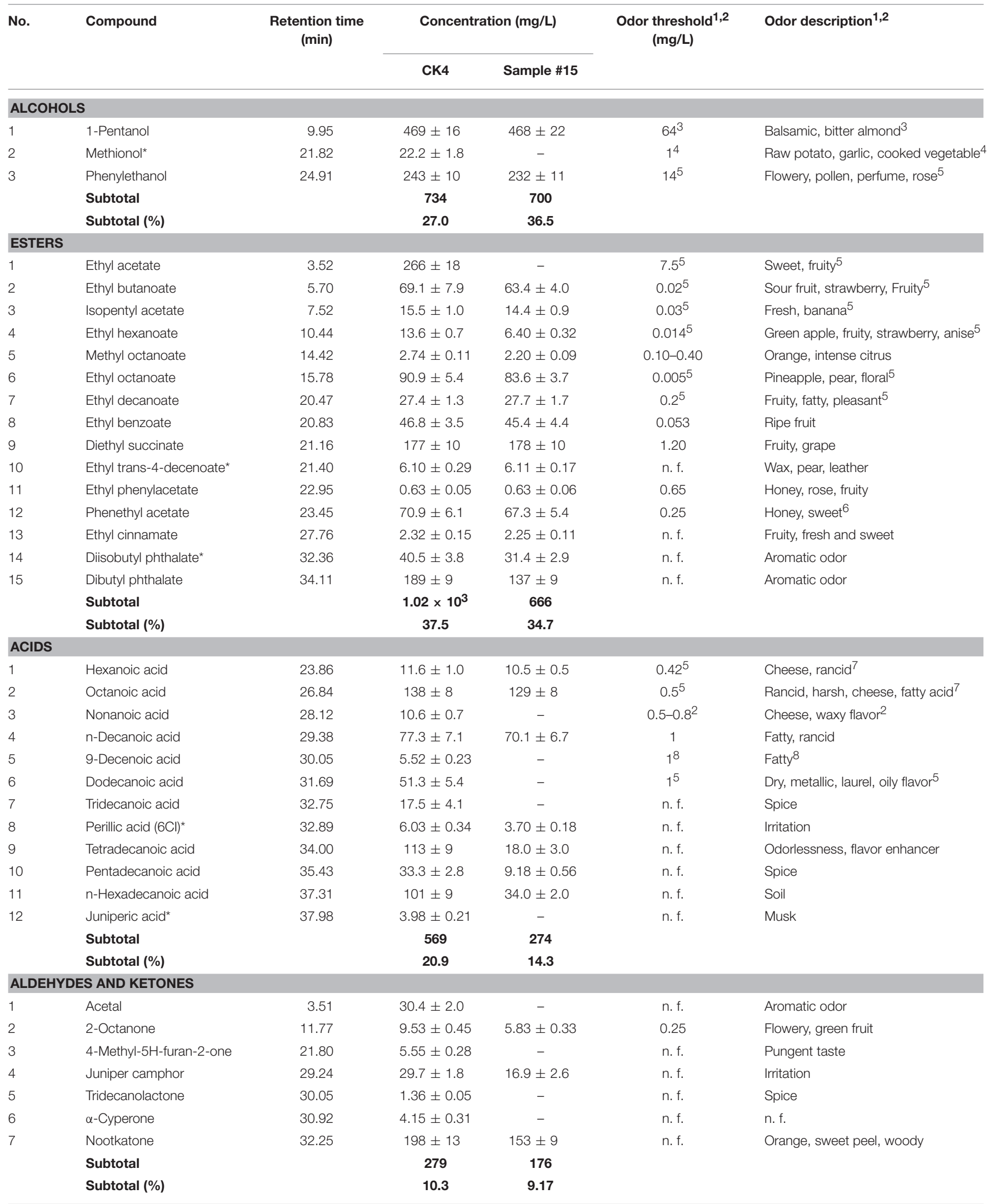


TABLE 3 | Continued

\begin{tabular}{|c|c|c|c|c|c|c|}
\hline \multirow[t]{2}{*}{ No. } & \multirow[t]{2}{*}{ Compound } & \multirow{2}{*}{$\begin{array}{l}\text { Retention time } \\
\text { (min) }\end{array}$} & \multicolumn{2}{|c|}{ Concentration (mg/L) } & \multirow{2}{*}{$\begin{array}{l}\text { Odor threshold }{ }^{1,2} \\
\qquad(\mathrm{mg} / \mathrm{L})\end{array}$} & \multirow[t]{2}{*}{ Odor description ${ }^{1,2}$} \\
\hline & & & CK4 & Sample \#15 & & \\
\hline \multicolumn{7}{|c|}{ TERPENES } \\
\hline 1 & Linalool & 18.40 & $13.8 \pm 1.2$ & $13.6 \pm 2.1$ & $0.025^{9}$ & Flowery, fruity, muscat ${ }^{8}$ \\
\hline 2 & (-)-4-Terpineol & 19.60 & $4.08 \pm 0.29$ & $3.29 \pm 0.17$ & 0.12 & Flowers, clove \\
\hline 5 & Geranylacetone & 24.08 & $7.86 \pm 0.44$ & $5.92 \pm 0.39$ & 0.06 & Magnolia, green \\
\hline 6 & $\beta$-Ionone & 25.29 & $5.40 \pm 0.26$ & - & $0.00009^{5}$ & Violet, sweet fruity ${ }^{8}$ \\
\hline 7 & Trans-nerolidol & 26.64 & $2.91 \pm 0.09$ & $3.13 \pm 0.16$ & $0.7^{7}$ & Sweet fruity, floral ${ }^{5}$ \\
\hline \multirow[t]{2}{*}{8} & Farnesol & 30.34 & $24.4 \pm 2.0$ & $25.6 \pm 1.1$ & 1 & Sweet, floral, fragrant \\
\hline & Subtotal & & 86.2 & 80.5 & & \\
\hline 2 & 2-Methoxy-4-vinylphenol & 28.51 & $21.4 \pm 1.7$ & $17.3 \pm 2.0$ & 0.04 & Spicy, clove, curry powder \\
\hline 3 & 2,4-Di-tert-butylphenol* & 29.79 & $5.64 \pm 0.25$ & $3.87 \pm 0.19$ & 0.20 & Carbolic acid \\
\hline 4 & Guaiazulene & 37.77 & $1.80 \pm 0.05$ & - & n. f. & n. f. \\
\hline \multirow[t]{4}{*}{5} & Squalene & 41.34 & $3.55 \pm 0.16$ & $3.91 \pm 0.23$ & n. f. & Pleasant, aromatic \\
\hline & Subtotal & & 33.7 & 25.1 & & \\
\hline & Subtotal (\%) & & 1.24 & 1.31 & & \\
\hline & Total (mg/L) & & $2.72 \times 10^{3}$ & $1.92 \times 10^{3}$ & & \\
\hline
\end{tabular}

n. f., not found.

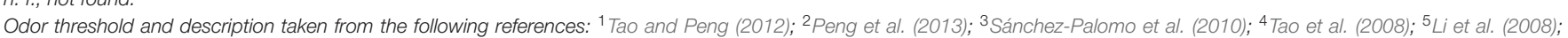
${ }^{6}$ Barata et al. (2011); ${ }^{7}$ Li (2006); ${ }^{8}$ Sun and Liu (2004); ${ }^{9}$ Aznar et al. (2003). All data are expressed as the mean \pm standard deviation of three replicates from two citrus wine samples.

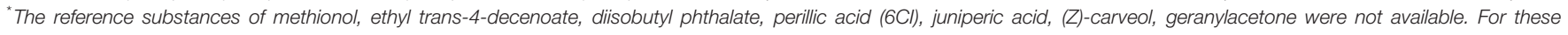
compounds the calibration curves of terpineol, ethyl 4-decenoate, dibutyl phthalate, 9-Decenoic acid, dodecanoic acid, cis-3-hexen-1-ol, $\alpha$-ionone, respectively, were used.

TABLE 4 | Total concentrations of compounds with an OAV $\geq 1$ in CK4 and sample \#15.

\begin{tabular}{llcc}
\hline No. & Compound & \multicolumn{2}{c}{ Concentration $(\mathbf{m g} / \mathbf{L})$} \\
\cline { 3 - 4 } & & CK4 & Sample \#15 \\
\hline 1 & Alcohols & 734 & 700 \\
& Subtotal (\%) & 27.0 & 36.5 \\
& Esters & $1.02 \times 10^{3}$ & 666 \\
3 & Subtotal (\%) & 37.5 & 34.7 \\
& Acids & 569 & 274 \\
4 & Subtotal (\%) & 20.9 & 14.3 \\
& Aldehydes and ketones & 279 & 176 \\
& Subtotal (\%) & 10.3 & 9.17 \\
& Terpenes & 86.2 & 80.5 \\
& Subtotal (\%) & 3.17 & 4.19 \\
& Others & 33.7 & 25.1 \\
& Subtotal (\%) & 1.24 & 1.31 \\
& Total (mg/L) & $2.72 \times 10^{3}$ & $1.92 \times 10^{3}$ \\
\hline
\end{tabular}

it remained higher in sample \#15 compared to the control. Evaluation of $a^{*}$ showed that sample \#15 and CK4 were green, with greater color intensity found in sample \#15, and following thermal stability testing, the color of sample \#15 and CK4 turned red, with sample \#15 appearing redder. Next, evaluation of the $b^{*}$ values indicated that sample \#15 and CK4 were yellow, with greater color intensity found in CK4, and that the color intensity for both increased following thermal stability testing. We also found from values of $C^{*}$ that the color saturation of sample \#15 and CK4 was low, and that the degree of color saturation increased following thermal stability testing. The values of $H^{*}$ were all less than zero and, with respect to the general tendency of colors, sample \#15 and CK4 appeared blue. Based on results from our thermal stability experiments, we found that the values of $H^{*}$ were greater than zero, with a general color tendency of red for both sample \#15 and CK4. Finally, based on values of $E^{*}$, before and after heating stability experiments, a $\Delta \mathrm{E}$ $<3$ revealed no discernible difference between sample \#15 and CK4.

As shown in Table 3 and Figure 2, it is evident that the number of components and the quantity of VCCs in citrus wine declined after fining from 50 to 36 and from $2.72 \times 10^{3}$ to $1.92 \times 10^{3} \mathrm{mg} / \mathrm{L}$, respectively. We found that the number of alcohols ( 3 vs. 2 ), esters (15 vs. 14 ), acids (12 vs. 7 ), aldehydes and ketones ( 7 vs. 3 ), and terpenes ( 8 vs. 7 ) decreased in sample \#15, relative to that in CK4. Table 4 shows that we found similar reductions in the total concentration of chemical compounds with an $\mathrm{OAV} \geq 1$ in CK4 and sample \#15 for alcohols (734 vs. $700 \mathrm{mg} / \mathrm{L})$, esters $\left(1.02 \times 10^{3}\right.$ vs. $\left.666 \mathrm{mg} / \mathrm{L}\right)$, acids (569 


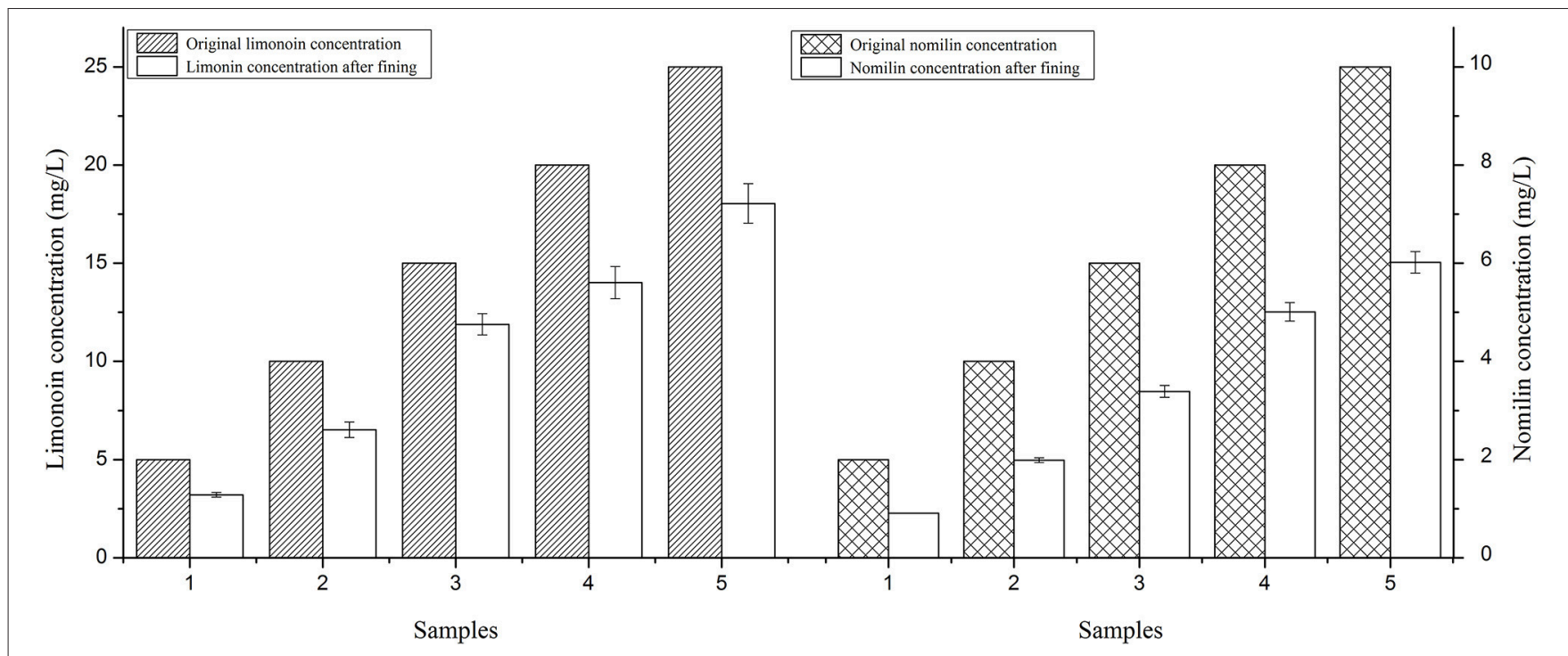

FIGURE 3 | Limonin and nomilin concentrations in citrus wine model sample \#15 treated with 125 mg/L agar and 30 mg/L gelatin.

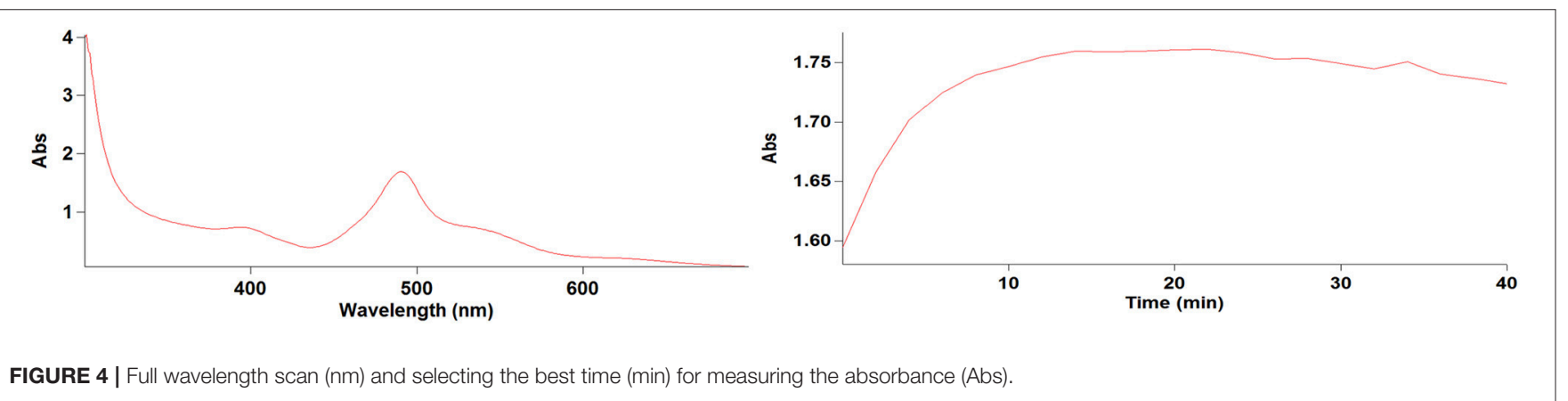

vs. $274 \mathrm{mg} / \mathrm{L}$ ), aldehydes and ketones (279 vs. $176 \mathrm{mg} / \mathrm{L})$, and terpenes $(86.2$ vs. $80.5 \mathrm{mg} / \mathrm{L})$. We also found that the higher concentrations of phenylethanol in CK4 and sample \#15 were 243 and $232 \mathrm{mg} / \mathrm{L}$, respectively. Higher alcohols are secondary yeast metabolites and the optimal levels (below $300 \mathrm{mg} / \mathrm{L}$ ) impart flowery, pollen, perfume, and rose characteristics (Li et al., 2008; Bartowsky and Pretorius, 2009).

\section{Verification Test Analysis}

As shown in Figure 3, after treatment with $125 \mathrm{mg} / \mathrm{L}$ agar and 30 $\mathrm{mg} / \mathrm{L}$ gelatin as fining agents, the concentrations of limonin and nomilin in the citrus wine model systems decreased by differing degrees. It was further confirmed that using $125 \mathrm{mg} / \mathrm{L}$ agar and $30 \mathrm{mg} / \mathrm{L}$ gelatin as fining agents can reduce the concentration of limonoids in citrus wine.

Liang et al. (2013) found that the capacities of activated carbon and diatomite for adsorbing bitter substances was similar, while also possessing a clarifying role. Gelatin and agar have a positive and negative charge, respectively, and because of attractive effects, their interactions and coagulation can increase the surface area resulting in greater adsorption, thereby reducing the effects of bitter substances, such as total triterpenes (like limonoids). In addition, in the case of turbidity, gelatin and agar can interact with both positive and negative charges in the liquor, thus promoting greater overall clarification (Soto-Peralta et al., 1989). Importantly, gelatin (Fischerleitner et al., 2003) and agar can combine with phenolic substances, which in citrus includes naringin, hesperidin, and tannin with bitter citrus polyphenols (Balasundram et al., 2006), thereby neutralizing precipitation and reducing bitter taste. Finally, gelatin and agar lighten citrus wine by adsorbing pigment.

\section{CONCLUSIONS}

Fining of fruit wine is an important part of the brewing process. In this study, we evaluated alternative uses of several adsorptive fining agents (agar, gelatin, chitosan, diatomite, bentonite, PVPP, and casein) at different concentrations with the aim of reducing the intensity of DB in citrus wine. Fining with almost all seven agents decreased the limonoid concentration, and our findings from single-factor, $\mathrm{L}_{3}^{4}$, and $\mathrm{L}_{2}^{3}$ fining experiments show that the concentration of limonoids decreased by $1.58-46.40 \%, 24.71-$ $35.26 \%$, and $19.65-27.78 \%$, respectively, as we optimized the mixtures and concentrations of fining agents. We discovered that the combination of fining agents that provided the best results, as compared to control citrus wine samples, was $125 \mathrm{mg} / \mathrm{L}$ agar and 
$30 \mathrm{mg} / \mathrm{L}$ gelatin. Our findings consistently demonstrated that this combination of fining agents (sample \#15 in this study) not only produced citrus wine with reduced DB intensity, but also clarified the wine body, achieved a larger net amount of precipitation, increased the retention rate of ascorbic acid, retained antioxidant activity, and maintained the special color of citrus wine. Finally, we also explored the sensory and aroma implications of using this combination of fining agents; however, a more intensive investigation into this aspect of fined citrus wine is warranted.

Because our study was conducted in an industrial setting, it provides an important link between the research and industry sectors, thereby allowing for a more effective translation of our results by commercial winemakers. Further investigation to determine how fining agents like gelatin, agar, and chitosan affect the concentrations of triterpenoids in citrus wine is required.

\section{AUTHOR CONTRIBUTIONS}

HL and JB conceived and designed the experiments. HW not only contributed reagents, materials, analysis tools, and guided

\section{REFERENCES}

Abbasi, S., Zandi, P., and Mirbagheri, E. (2005). Quantitation of limonin in Iranian orange juice concentrates using high-performance liquid chromatography and spectrophotometric methods. Eur. Food Res. Technol. 221, 202-207. doi: 10.1007/s00217-005-1136-1

Andrew, P., Breksa, III., and Ibarra, P. Jr. (2007). Colorimetric method for the estimation of total limonoid aglycones and glucoside contents in citrus juices. J. Agric. Food Chem. 55, 5013-5017. doi: 10.1021/jf063731c

Aznar, M., López, R., Cacho, J., and Ferreira, V. (2003). Prediction of aged red wine aroma properties from aroma chemical composition. Partial least squares regression models. J. Agric. Food Chem. 51, 2700-2707. doi: 10.1021/jf026115z

Balasundram, N., Sundram, K., and Samman, S. (2006). Phenolic compounds in plants and agri-industrial by-products; Antioxidant activity, occurrence, and potential uses. Food Chem. 99, 191-203.2727. doi: 10.1016/j.foodchem.2005.07.042

Barata, A., Campo, E., Malfeito-Ferreira, M., Loureiro, V., Cacho, J., and Ferreira, V. (2011). Analytical and sensorial characterization of the aroma of wines produced with sour rotten grapes using GC-O and GC-MS: identification of key aroma compounds. J. Agric. Food Chem. 59, 2543-2553. doi: 10.1021/jf104141f

Bartowsky, E. J., and Pretorius, I. S. (2009). "Microbial formation and modification of flavor and off-Flavor compounds in wine," in Biology of Microorganisms on Grapes, in Must and in Wine, eds K. Helmut, U. Gottfried, and F. Jürgen (Berlin: Springer-verlag Berlin), 209-231.

Berhow, M. A., Hasegawa, S., and Manners, G. D. (2000). "Citrus limonoid research: an overview," in Citrus Limonoids, Functional Chemicals in Agriculture and Food, eds M. A. Berhow, S. Hasegawa, and G. D. Manners (Washington, DC: American Chemical Society), 1-8.

Cemeroglu, B. (1992). Basic Analysis Methods in Fruit and Vegetable Processing Industry. Ankara: Biltav Press.

Champagne, D. E., Koul, O., Isman, M. B., Scudder, G. G. E., and Towers, G. H. N. (1992). Biological activity of limonoids from the Rutales. Phytochemistry $31,377-394$.

FAO, (2016) Citrus: Food and Agriculture. Food and Agriculture Organization of the United Nations. Available online at: http://www.fao.org/faostat/zh/\#search/ citrus (Accessed April 20, 2016).

Fischerleitner, E., Wendelin, S., and Eder, R. (2003). Comparative study of vegetable and animal proteins used as fining agents. Bull. O.I.V. 76, 30-52.

Gadow, A. V., Joubert, E., and Hansmann, C. F. (1997). Comparison of the antioxidant activity of aspalathin with that of other plant phenols of rooibos the experiment, but also modified the language of the manuscript. JB carried out the experiments, analyzed the data, and wrote the manuscript. All authors have reviewed and approved the manuscript for publication.

\section{ACKNOWLEDGMENTS}

The authors would like to thank the Special Agricultural Finance in Shaanxi Province-2016 Technical System Construction for the Grape Industry in Shaanxi Province and the Science \& Technology Program Project of Shaanxi Province Study on the Geographical Origin Identification of Grape Variety Meili by Elemental Analysis (2017NY-107) for providing financial assistance.

\section{SUPPLEMENTARY MATERIAL}

The Supplementary Material for this article can be found online at: https://www.frontiersin.org/articles/10.3389/fchem. 2019.00185/full\#supplementary-material tea (Aspalathus linearis), $\alpha$-tocopherol, BHT, and BHA. J Agric Food Chem. 45, 632-638. doi: 10.1021/jf960281n

Glabasnia, A., Dunkel, A., Frank, O., and Hofmann, T. (2018). Decoding the nonvolatile sensometabolome of orange juice (Citrus sinensis). J. Agric. Food Chem. 66, 2354-2369. doi: 10.1021/acs.jafc.7b 06142

Granato, T. M., Nasi, A., Ferranti, P., Iametti, S., and Bonomi, F. (2014). Fining white wine with plant proteins, effects of fining on proanthocyanidins and aroma components. Eur Food Res Technol. 238, 265-274. doi: 10.1007/s00217-013-2108-5

Guadagni, D. G., Maier, V. P., and Turnbaugh, J. G. (1973). Effect of some citrus juice constituentson taste thresholds for limonin and naringin bitterness. J. Sci. Food Agric. 24, 1277-1288. doi: 10.1002/jsfa.2740241018

Jackson, R. S. (2014). Wine Science, Principals and Applications (Food Science and Technology). Amsterdam: Academic Press.

Kimball, D. A. (1991). Citrus Processing Quality Control and Technology. New York, NY: AVI.

Kranz, P., Adler, P., and Kunz, B. (2011). Sorption of citrus flavour compounds on XAD-7HP resin during the debittering of grapefruit juice. Int. J. Food Sci. Tech. 46, 30-36. doi: 10.1111/j.1365-2621.2010.02442.x

Lee, H. S., and Kim, J. G. (2003). Effects of debittering on red grapefruit juice concentrate. Food Chem. 82, 177-180. doi: 10.1016/S0308-8146(02)00280-7

Li, H. (2002). Grape wine brewing in small containers. Liq. Makin. Sci. Technol. 74, 70-71. doi: 10.3969/j.issn.1001-9286.2002.04.023

Li, H. (2006). Smell and Wine Odor Analysis. Wine Tasting, 1st Edn. Beijing: China Science Press.

Li, H., Tao, Y. S., Wang, H., and Zhang, L. (2008). Impact odorants of chardonnay dry white wine from Changli County (China). Eur. Food Res. Technol. 227, 287-292. doi: 10.1007/s00217-007-0722-9

Li, H., Wang, H., Yuan, C. L., and Wang, S. S.,(2012). Wine Technology. Xi An: Science Press.

Liang, Q. R., Zhao, J. F., and Wei, F. F. (2013). Prepared fermented wine of shatang orange from Sihui. Food Res. Dev. 34, 43-46. doi: 10.3969/j.issn.1005-6521.2013.04.014

Luo, A. X., Chen, Y. L., Liu, Y. H., Gao, L. L., Ruan, R. S., and Lin, X. Y. (2007). Study on clarification of persimmon Wine. Food Sci. 28, 304-308. doi: 10.3321/j.issn:1002-6630.2007.10.073

Maier, V. P., Bennett, R. D., and Hasegawa, S. (1977). "Limonin and other limonoids," in Citrus Science and Technology, eds S. Nagy, P. E. Shaw, and M. K. Veldhuis (Westport: The AVI Publishing Company, Inc), 335-396. 
Maier, V. P., Hasegawa, S., Bennett, R. D., and Echols, L. C. (1980). "Limonin and limonoids," in Citrus Nutrition and Quality, eds S. Nagy and J. A. Attaway (Washington, DC: American Chemical Society), 63-82.

Peng, C. T., Wen, Y., Tao, Y. S., and Lan, Y. Y. (2013). Modulating the formation of Meili wine aroma by prefermentative freezing process. J. Agric. Food Chem. 61, 1542-1553. doi: 10.1021/jf3043874

Perestrelo, R., Fernandes, A., Albuquerque, F. F., Marques, J. C., and Câmara, J. S. (2006). Analytical characterization of the aroma of Tinta Negra Mole red wine: identification of the main odorants compounds. Anal. Chim. Acta. 563, 154-164. doi: 10.1016/j.aca.2005.10.023

Pérez-Caballero, V., Ayala, F., Echávarri, J. F., and Negueruela, A. I. (2003). Proposal for a new standard oiv method for determination of chromatic characteristics of wine. Am. J. Enol. Viticult. 54, 59-62.

Puri, A. (1990). "Removal of bitter compounds from citrus compounds by adsorption techniques," in Bitterness in Food and Beverages. Developments in Food Science Series, ed R. L. Rouself (Amsterdam: Elsevier Science Publishing Company), 325-336.

Ramos-Escudero, F., González-Miret, M. L., and García-Asuero, A. (2012). Effect of various extraction systems on the antioxidant activity kinetic and color of extracts from purple corn. Vitae 19, 41-48.

Re, R., Pellegrini, N., Proteggente, A., Pannala, A., Yang, M., and Rice-Evans, C. (1999). Antioxidant activity applyingan improved ABTS radical cation decolorization assay. Free Radical Bio. Med. 26, 1231-1237.

Rouseff, R. L. (1982). Nomilin, a new bitter component in grapefruit juice. J. Agric. Food Chem. 30, 504-507.

Rousseff, R. L., and Matthews, R. F. (1984). Nomilin, taste threshold and relative bitterness. J. Food Sci. 49, 777-779. doi: 10.1111/j.1365-2621.1984.tb13209.x

Roy, A., and Saraf, S. (2006). Limonoids, overview of significant bioactive triterpenes distributed in plants kingdom. Biol. Pharm Bull. 29, 191-201. doi: $10.1248 /$ bpb. 29.191

Sánchez-Palomo, E., García-Carpintero, E. G., Alonso-Villegas, R., and González-Viñas, M. A. (2010). Characterization of aroma compounds of Verdejo white wines from the La Mancha region by odour activity values. Flavour Frag. J. 25, 456-462. doi: 10.100 2/ffj. 2005

Soto-Peralta, N. V., Müller, H., and Knorr, D. (1989). Effects of chitosan treatments on the clarity and color of apple juice. J. Food Sci. 54, 495-496. doi: 10.1111/j.1365-2621.1989.tb03119.x

Sun, B. G., and Liu, Y. P. (2004). Food Spice and Flavor Handbook. 1st Edn. Beijing: China Petroleum Press.
Tao, Y. S., Li, H., Wang, H., and Zhang, L. (2008). Volatile compounds of young cabernet sauvignon red wine from changli county (china). J. Food Comp. Anal. 21, 689-694. doi: 10.1016/j.jfca.2008. 05.007

Tao, Y. S., and Peng, C. T. (2012). Correlation analysis of aroma characters and volatiles in Chardonnay dry white wines from five districts in China. Transact. Chin. Soc. Agric. Machin. 33, 130-139. doi: 10.6041 /j.issn.1000-1298.2012.03.025

Vieira, S. I., Ferreira-Dias, S., and Ribeiro, M. H. (2009). Bitterness reduction of limonin by selective adsorption onto new polymeric resins. New Biotechnol. 255, S186-S187. doi: 10.1016/j.nbt.2009.06.739

Wang, F., Deng, Q., Duan, W. L., Sun, Y. X., and Bao, Y. H. (2016). Optimization of clarification effect of blueberry wine using composite clarifier by response surface methodology. J. Chin. Inst. Food Sci. Technol. 16, 149-158. doi: 10.16429/j.1009-7848.2016.08.021

Wang, X., Zhang, H. N., Ma, Y. K., Ye, H., Zhang, L., Li, J. F., et al. (2015). Dynamic changes in phenolics and their antioxidant activities during the fermentation of blueberry wine. Moder. Food Sci. Technol. 31, 90-95. doi: 10.13982/j.mfst.1673-9078.2015.1.017

Wang, X. J., Tao, Y. S., Wu, Y., An, R. Y., and Yue, Z. Y. (2017). Aroma compounds and characteristics of noble-rot wines of Chardonnay grapes artificially botrytized in the vineyard. Food Chem. 226, 41-50. doi: 10.1016/j.foodchem.2017.01.007

Wu, H. J., Sun, Z. G., and Wang, H. (2006). Study on the development of citrus processing industries in China. Food Ferment. Ind. 32, 85-89. doi: 10.3321/j.issn:0253-990X.2006.04.024

Xi, Z. M., Tao, Y. S., Zhang, L., and Li, H. (2011). Impact of cover crops in vineyard on the aroma compounds of Vitis vinifera L. cv Cabernet Sauvignon wine. Food Chem. 127, 516-522. doi: 10.1016/j.foodchem.2011.01.033

Conflict of Interest Statement: The authors declare that the research was conducted in the absence of any commercial or financial relationships that could be construed as a potential conflict of interest.

Copyright (c) $2019 \mathrm{Bi}, \mathrm{Li}$ and Wang. This is an open-access article distributed under the terms of the Creative Commons Attribution License (CC BY). The use, distribution or reproduction in other forums is permitted, provided the original author(s) and the copyright owner(s) are credited and that the original publication in this journal is cited, in accordance with accepted academic practice. No use, distribution or reproduction is permitted which does not comply with these terms. 